\title{
Article \\ Attitudes of Undergraduate Nursing Students towards Patient Safety: A Quasi-Experimental Study
}

\author{
Nuria Cantero-López ${ }^{1}{ }^{1}$, Víctor M. González-Chordá ${ }^{1, *} \mathbb{C}^{\mathbb{D}}$, María Jesús Valero-Chillerón ${ }^{1}{ }^{\mathbb{D}}$, \\ Desirée Mena-Tudela ${ }^{1}$ (D), Laura Andreu-Pejó ${ }^{1}$ (D), Rafael Vila-Candel ${ }^{2,3}{ }^{(D)}$ and Águeda Cervera-Gasch ${ }^{1}$ (D) \\ 1 Department of Nursing, Faculty of Health Sciences, Universitat Jaume I, 12071 Castellón, Spain; \\ al362075@uji.es (N.C.-L.); chillero@uji.es (M.J.V.-C.); dmena@uji.es (D.M.-T.); pejo@uji.es (L.A.-P.); \\ cerveraa@uji.es (Á.C.-G.) \\ 2 Department of Obstetrics and Gynaecology, La Ribera University Hospital, FISABIO, Crta. Corbera km 1, \\ 46600 Valencia, Spain; vila_rafcan@gva.es \\ 3 Department of Nursing, Faculty of Nursing and Podiatry, University of Valencia, Jaume Roig, s/n, \\ 46010 Valencia, Spain \\ * Correspondence: vchorda@uji.es; Tel.: +34-964-387-744
}

\section{check for} updates

Citation: Cantero-López, N.; González-Chordá, V.M.;

Valero-Chillerón, M.J.; Mena-Tudela, D.; Andreu-Pejó, L.; Vila-Candel, R.; Cervera-Gasch, Á. Attitudes of Undergraduate Nursing Students towards Patient Safety: A Quasi-Experimental Study. Int. J. Environ. Res. Public Health 2021, 18, 1429. https://doi.org/10.3390/ ijerph18041429

Academic Editor: Paul B. Tchounwou

Received: 4 January 2021

Accepted: 1 February 2021

Published: 3 February 2021

Publisher's Note: MDPI stays neutral with regard to jurisdictional claims in published maps and institutional affiliations.

Copyright: (C) 2021 by the authors Licensee MDPI, Basel, Switzerland. This article is an open access article distributed under the terms and conditions of the Creative Commons Attribution (CC BY) license (https:// creativecommons.org/licenses/by/ $4.0 /)$.

\begin{abstract}
Improving nursing students' attitudes towards patient safety is a current and relevant topic This study aims to evaluate the effectiveness of an educational intervention based on critical incident and root cause analysis (RCA) techniques regarding attitudes towards patient safety in nursing students. A quasi-experimental before and after study was developed between January 2018 and December 2019 in a sample of 100 nursing students at Universitat Jaume I (Spain). The intervention was developed in two phases. Phase I was at university, where students applied the RCA technique in a real case. Phase II took place during clinical practice. Students used critical incidents to identify a risk situation for the patients and applied RCA to detect its root causes. The measurement of attitudes was performed with the Attitudes to Patient Safety Questionnaire (APSQ-III). The global score of the questionnaire in the baseline measurement was $3.911( \pm 0.335)$, in the intermediate measurement it was $4.031( \pm 0.337)$ and in the final measurement it was $4.052( \pm 0.335)$, with significant differences $(p=0.03)$. However, intra-group differences were observed in the final measurement $(p=0.021)$. The teamwork dimension had the highest mean score on all three measures and the notification dimension had the lowest mean scores. An educational intervention combining critical incident and RCA techniques can improves nursing students' attitudes toward patient safety.
\end{abstract}

Keywords: nurse education; patient safety; competence; attitude; critical incident technic; root cause analysis

\section{Introduction}

Since the beginning of the century, there has been growing concern with the education of future health professionals regarding the knowledge, skills and attitudes necessary to improve their competencies in patient safety. The World Health Organization (WHO) [1] and different agencies in the United States [2,3], Australia [4], Canada [5] and Europe [6] have developed competency profiles for patient safety that health science students must acquire, including nursing students.

However, around the world nursing degree curricula do not assign the necessary importance to competencies related to patient safety [7-10] and it is necessary to advance the design and evaluation of more effective educational interventions to improve knowledge, skills and attitudes regarding patient safety $[7,11]$, both in university classrooms and clinical settings [12,13].

In the literature, different approaches can be found to improve the competencies in patient safety of nursing students. Some authors use traditional approaches with master classes [14] or structured courses [15]. Other authors introduce digital recordings in their 
courses $[16,17]$ or use instructional methods such as the flipped classroom $[18,19]$. On the other hand, Lee and Quinn [13] conclude that clinical simulation, technological aids and online learning modules improve the safety competencies of nursing students. However, more research is needed to identify which educational strategies are the most appropriate, integrating theoretical and clinical learning [11,12].

During clinical practices, nursing students may witness situations that put patient safety at risk and may make errors that cause damage to their patients [20]. The most frequent errors are related to medication administration, the improper handling of equipment and biological accidents [21,22]. Despite the importance of knowing these errors to improve healthcare processes [23], nursing students are reluctant to report these situations for fear of the consequences [24], and it is necessary to improve their attitudes towards teamwork and open communication or error reporting [25]. In fact, Kong et al. [26] found an association between favorable attitudes of nursing students towards patient safety and the execution of related behaviors-for example, error notification-which also occurs when they are professionals [27].

Therefore, it is important to improve the attitudes of nursing students towards patient safety, although attitudes are probably one of the most complex components to introduce and evaluate in the teaching-learning process [28]. Student mistakes during practice can be considered learning opportunities; techniques initially developed in the field of engineering and industrial safety, such as critical incident [29] or root cause analysis (RCA) [30], can be used as teaching strategies to improve the attitudes of undergraduate nursing students towards patient safety.

In 1950, Flanagan defined a critical incident as "any observable human activity that is complete enough in itself to allow inferences and predictions about the person performing the act" and developed this retrospective technique of analysis of human behavior [31]. Since then, the critical incident technique has been used in nursing education to optimize learning from real experiences lived by students-for example, in the development of critical thinking, cultural and ethical aspects [29], or learning from evidence-based practice [32].

On the other hand, root cause analysis (RCA) is a reactive technique based on the assumption that problems are best solved by trying to correct or eliminate root causes, rather than simply trying to solve immediate consequences [33]. Several authors propose the use of RCA as a technique to teach patient safety to nursing students $[3,30]$, and other authors [34] conclude that this technique promotes critical thinking and a positive attitude in students when real cases are analyzed.

These techniques show favorable results when they are used as teaching methods, but a limited number of studies have evaluated the relationship between their effect on attitudes and patient safety in nursing students. Thus, the main objective of this study was to evaluate the effectiveness of an educational intervention based on critical incident and RCA techniques regarding attitudes related to patient safety in undergraduate nursing students at the Universitat Jaume I (Spain).

\section{Materials and Methods}

\subsection{Design and Settings}

A quasi-experimental before and after study was carried out in third-year students of the degree in nursing at Universitat Jaume I (Spain). The study was conducted between January 2018 and December 2019.

\subsection{Population and Sample}

The nursing degree at Universitat Jaume I has 360 students. The study population was made up of third-year students enrolled in the subject "Management of care in the socio-sanitary field" in the academic years 2017-2018 and 2018-2019 $(N=108)$. This subject has a total of six credits within the European Credit Transfer System (ECTS). The theoretical contents deal with aspects related to management models, leadership, quality of care and 
patient safety. The period of clinical practice is carried out in adult hospitalization units, where students carry out an activity that allows applying the theoretical contents of the subject in the healthcare reality.

Through a convenience sampling, all the students enrolled in this subject were included. Those who did not complete the clinical practice period and those who did not agree to participate in the study were excluded.

\subsection{Educational Intervention}

The educational intervention was based on RCA and critical incident techniques and was carried out in two phases, developing in the same way in the two academic years considered (Figure 1). Phase I was carried out in the classroom by the teacher responsible for the subject and a member of the research team. The duration was $120 \mathrm{~min}$. With no prior structured knowledge about patient safety, groups of five students applied the RCA technique in a real case related to errors in the administration of medication known as "The case of the Denver nurses" [35]. This case is based on real events and deals with the chain of human errors and system failures that occurred from the admission of a pregnant woman to the death of the baby due to an error in the administration of medication. The exercise was based on teaching materials on patient safety prepared by the Spanish Ministry of Health, Social Services and Equality [36]. In addition, the exercise included a series of questions to delve into the basic principles related to patient safety (e.g., whose fault was it?). The case was resolved and a guided reflection was carried out on the basic principles of patient safety.

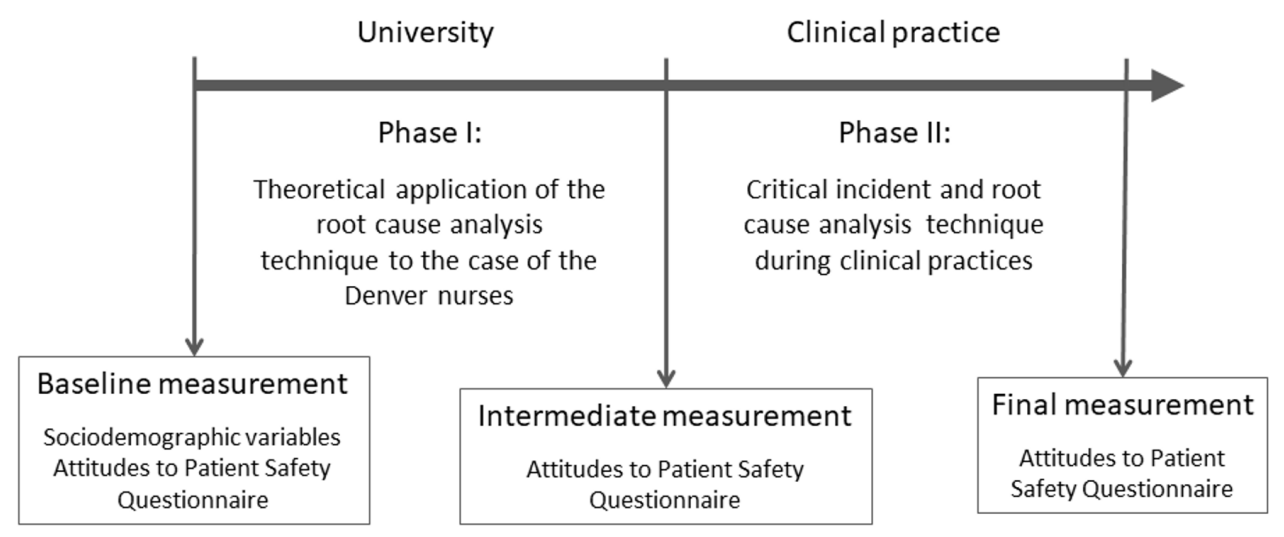

Figure 1. Study sequence.

Phase II was carried out during clinical practice. Individually, each student used the critical incident technique to analyze a situation experienced during clinical practices that posed a risk to patient safety and applied the RCA technique to that situation. Examples of critical incidents related to patient safety during clinical practices include errors in the administration of medication, the fall of a patient during mobilization or a failure to rescue. Likewise, each student carried out a bibliographic search to propose measures that could reduce or eliminate the root causes of this situation. The students had a guide to prepare the work and the support of the teaching staff of the subject.

\subsection{Data Collection Instrument}

Attitudes towards patient safety were assessed with the Attitudes to Patient Safety Questionnaire (APSQ-III). The original version of the APSQ-III was developed by Carruthers et al. [37] for medical students and Lamponi et al. [38] validated it in Spanish. In this study, a version for nursing students adapted and validated in a previous study pending publication was used. This version is composed of 22 items measured with a 5-point Likert scale (1, strongly disagree; 5, strongly agree) distributed in six dimensions that explained $53.82 \%$ of the variance in the exploratory factor analysis (Responsibility; 
Organization and communication; Teamwork; Training; Notification; Awareness). A confirmatory factor analysis indicates an adequate fit between the model and the data $\left(\chi^{2}=366\right.$; $p<0.001 ; \chi 2 / \mathrm{df}=1.886$; RMSEA $=0.07 ; 95 \% \mathrm{Cl}=0.059-0.081 ; \mathrm{CFI}=0.885)$. The questionnaire offered an adequate internal consistency $(\alpha=0.808)$ and a good intra-observer reliability $(I C C=0.792)$. A higher score on the questionnaire means better attitudes towards patient safety.

In addition, sociodemographic variables were collected, such as age, sex (female; male), academic year (2017-2018; 2018-2019), previous studies related to health sciences (no; university; professional training; others) and employment status (unemployed; active in the health field; not active in the health field).

\subsection{Data Collection Process}

Data collection took place between February and July, in the 2017-2018 and 2018-2019 academic years. A baseline measurement was performed, prior to the intervention, where sociodemographic variables were also collected. Likewise, an intermediate measurement was made after Phase I of the intervention and a final measurement after Phase II, at the end of the clinical practices. In the baseline measurement, the students received information about the objectives and methodology of the study, as well as its voluntary and anonymous nature. In all three measurements, scheduled classes were used to collect data.

\subsection{Data Analysis}

A descriptive analysis of the variables was carried out according to their nature. The effectiveness of the intervention was determined with the Friedman test for paired data, comparing the global scores of the questionnaire and its dimensions in the three measurements (baseline, intermediate and final) and with the Wilcoxon test for paired data, comparing two by two at each measurement.

In addition, a bivariate analysis was performed to determine if there were significant differences in the global score of the questionnaire in the three measurements (baseline, intermediate and final) based on sociodemographic variables. After confirming that the application conditions of the parametric tests (homoscedasticity and normality) were not met, the non-parametric Mann-Whitney U test was used for two groups and the KruskalWallis test for three or more groups. The qualitative variables were analyzed with the Chi-square test $(\mathrm{X} 2)$. The standard deviation $(S D)$ of the quantitative variables' mean was calculated. Statistical analysis was performed with SPSS program version 23.0 (IBM SPSS Statistics for Windows, IBM Corp., Armonk, NY, USA). The significance level was set at $p<0.05$.

\subsection{Ethical Considerations}

This study was approved and authorized by the Nursing Department Council of the Universitat Jaume I (project reference 19CO1/000156, 5 September 2019). In the baseline measurement, the participants were informed of the study objectives and its voluntary nature. Informed consent was obtained from all the subjects involved in the study. A dissociation code was used to relate the three measurements and ensure the anonymity of the participants. The study was designed and executed in accordance with Spanish Organic Law 03/2018 on Protection Personal Data and Guaranteeing Digital Rights and the ethical principles of the Declaration of Helsinki (beneficence, non-maleficence, autonomy and justice).

\section{Results}

\subsection{Sample Characteristics}

Eight participants were excluded because they did not adequately fill in the dissociation code in any of the three rounds. Thus, the final sample consisted of a total of 100 students. Fifty percent of the students belonged to the 2017-2018 academic year. The mean age of the sample was $22.54 \pm 5.92$ years and $78.8 \%(n=79)$ were women. There 
were no significant differences when comparing the participants according to academic year (Table 1).

Table 1. Sociodemographic variables according to academic year $(N=100)$.

\begin{tabular}{|c|c|c|c|c|}
\hline \multirow{2}{*}{\multicolumn{2}{|c|}{ Variables }} & \multicolumn{2}{|c|}{ Academic Year } & \multirow{2}{*}{$p^{1}$} \\
\hline & & \multirow{2}{*}{$\begin{array}{c}\mathbf{2 0 1 7 - 2 0 1 8 \% ( n )} \\
34.8(32)\end{array}$} & \multirow{2}{*}{$\frac{\mathbf{2 0 1 8 - 2 0 1 9 \%}(\boldsymbol{n})}{37.0(34)}$} & \\
\hline & Not employed & & & \multirow{3}{*}{0.224} \\
\hline Employment situation & Not in the health area & $10.9(10)$ & $7.6(7)$ & \\
\hline & In the health area & $7.6(7)$ & $2.1(2)$ & \\
\hline \multirow{2}{*}{$\operatorname{Sex}(n=99)$} & Female & $40.4(40)$ & $38.4(38)$ & \multirow{2}{*}{0.766} \\
\hline & Male & $10.1(10)$ & $11.1(11)$ & \\
\hline \multirow{4}{*}{$\begin{array}{l}\text { Previous studies } \\
\qquad(n=90)\end{array}$} & No & $36.7(33)$ & $37.8(34)$ & \multirow{4}{*}{0.182} \\
\hline & University & $4.4(4)$ & $0(0)$ & \\
\hline & Professional training & $11.1(10)$ & $8.9(8)$ & \\
\hline & Other & $1.1(1)$ & $0(0)$ & \\
\hline \multicolumn{2}{|c|}{ Variables } & m (SD) & m (SD) & $p^{2}$ \\
\hline \multicolumn{2}{|c|}{ Age $(n=100)$} & $22.50(4.31)$ & $22.58(7.23)$ & 0.122 \\
\hline
\end{tabular}

${ }^{1}$ Chi-square test; ${ }^{2}$ Mann-Whitney U test.

\subsection{Effectiveness of the Educational Intervention}

The global score of the questionnaire in the baseline measurement was $3.91 \pm 0.34$ points, increasing in the intermediate measurement $(4.03 \pm 0.34)$ and in the final measurement $(4.05 \pm 0.34)$. The Friedman test confirmed the overall effectiveness of the intervention when comparing the three measurements $(p=0.03)$. Likewise, statistically significant differences were found between the baseline and the intermediate measurement $(p=0.008)$, but not between the intermediate and the final measurement $(p=0.664)$.

Table 2 shows the analysis of the scores obtained in the different dimensions. Responsibility $(p=0.004)$, Training $(p=0.001)$ and Awareness $(p=0.047)$ showed statistically significant differences when comparing the mean scores of the three measurements. However, no dimension showed significant differences when comparing the mean score of the intermediate and the final measurement $(p>0.05)$. On the other hand, the Teamwork dimension obtained the highest score in the three measurements, while the lowest scores were for the Notification dimension.

Table 2. Analysis of the dimensions of the questionnaire $(N=100)$.

\begin{tabular}{ccccccc}
\hline \multirow{2}{*}{ Dimensions } & $\mathbf{B M}^{\mathbf{1}}$ & $\mathbf{I M}^{\mathbf{1}}$ & $\mathbf{F M}^{\mathbf{1}}$ & \multicolumn{3}{c}{$\boldsymbol{p}$} \\
\cline { 2 - 7 } & $\mathbf{m} \mathbf{( S D )}$ & $\mathbf{m} \mathbf{( S D )}$ & $\mathbf{m}$ (SD) & BM-IM-FM $^{\mathbf{2}}$ & BM-IM $^{\mathbf{3}}$ & IM-FM $^{\mathbf{3}}$ \\
\hline Responsibility & $3.42(0.58)$ & $3.77(0.62)$ & $3.81(0.68)$ & 0.004 & $<0.001$ & 0.868 \\
Organization y & $4.32(0.55)$ & $4.38(0.47)$ & $4.41(0.60)$ & 0.341 & 0.517 & 0.830 \\
communication & $4.45(0.48)$ & $4.44(0.51)$ & $4.42(0.57)$ & 0.820 & 0.915 & 0.576 \\
Teamwork & $3.93(0.49)$ & $4.11(0.50)$ & $4.24(0.53)$ & 0.001 & 0.007 & 0.168 \\
Training & $3.36(0.92)$ & $3.18(0.98)$ & $3.25(0.82)$ & 0.377 & 0.090 & 0.864 \\
Notification & $4.02(0.70)$ & $4.28(0.68)$ & $4.18(0.66)$ & 0.047 & 0.001 & 0.055 \\
Awareness & &
\end{tabular}

${ }^{1}$ BM: Baseline measurement; IM: Intermediate measurement; FM: Final measurement; ${ }^{2}$ Friedman test; ${ }^{3}$ Wilcoxon test.

\subsection{Analysis of the Global Score of the Questionnaire According to Sociodemographic Variables}

Table 3 shows the results of the questionnaire score according to the sociodemographic variables. On the one hand, no significant differences were observed as a function of sex in any of the three measurements $(p>0.05)$. On the other hand, the students who worked in the health field obtained a significantly lower score in the three measurements $(p<0.05)$ and this score decreased throughout the educational intervention, although not significantly ( $p=0.223)$. In addition, students without previous studies related to health sciences obtained higher scores in the three measurements, although significant differences were only found in the intermediate measurement $(p=0.042)$. Finally, it was observed that 
the students of the 2018-2019 academic year obtained slightly higher scores in the three measurements, although there were only statistically significant differences in the final measurement $(p=0.021)$.

Table 3. Analysis of the global score of the questionnaire according to the sociodemographic variables $(N=100)$.

\begin{tabular}{|c|c|c|c|c|c|c|}
\hline \multirow{3}{*}{ Variables } & \multicolumn{6}{|c|}{ Measurements (m; SD) } \\
\hline & \multicolumn{2}{|c|}{ Baseline } & \multicolumn{2}{|c|}{ Intermediate } & \multicolumn{2}{|c|}{ Final } \\
\hline & $(\mathrm{m} ; \mathrm{SD})$ & $p$ & $(\mathrm{~m} ; \mathrm{SD})$ & $p$ & $(\mathrm{~m} ; \mathrm{SD})$ & $p$ \\
\hline Employment situation ${ }^{1}$ & & 0.016 & & 0.011 & & 0.044 \\
\hline Not employed & $3.96(0.32)$ & & $4.08(0.33)$ & & $4.09(0.40)$ & \\
\hline Not in the health area & $3.71(0.37)$ & & $4.06(0.35)$ & & $4.04(0.47)$ & \\
\hline In the health area & $3.80(0.24)$ & & $3.70(0.19)$ & & $3.46(0.54)$ & \\
\hline $\operatorname{Sex}^{2}$ & & 0.524 & & 0.527 & & 0.639 \\
\hline Female & $3.90(0.32)$ & & $4.04(0.34)$ & & $4.07(0.37)$ & \\
\hline Male & $3.96(0.39)$ & & $3.99(0.35)$ & & $3.99(0.57)$ & \\
\hline Previous studies ${ }^{1}$ & & 0.490 & & 0.042 & & 0.229 \\
\hline No & $3.93(0.35)$ & & $4.10(0.32)$ & & $4.11(0.41)$ & \\
\hline University & $3.73(0.15)$ & & $3.65(0.14)$ & & $3.86(0.0)$ & \\
\hline Professional training & $3.92(0.33)$ & & $3.93(0.35)$ & & $3.86(0.54)$ & \\
\hline Other & $4.28(0.0)$ & & $4.37(0.0)$ & & $4.37(0.0)$ & \\
\hline Academic year $^{2}$ & & 0.247 & & 0.434 & & 0.021 \\
\hline 2017-2018 period & $3.87(0.38)$ & & $\begin{array}{c}4.009 \\
(0.347)\end{array}$ & & $3.94(0.48)$ & \\
\hline 2018-2019 period & $3.95(0.28)$ & & $4.06(0.33)$ & & $4.16(0.32)$ & \\
\hline
\end{tabular}

${ }^{1}$ Kruskal-Wallis test; ${ }^{2}$ Mann-Whitney U test.

\section{Discussion}

The main findings of this study showed a significant increase in the global score of the APSQ-III questionnaire adapted for nursing students throughout the three measurements, so that it can be affirmed that this educational intervention based on the RCA and critical incident techniques significantly improved the attitudes towards patient safety. Other authors $[18,19,39]$ also carried out educational interventions aimed at improving the patient safety competencies of nursing students, but it is difficult to compare our results, as other studies with a similar educational intervention were not found and most of them evaluate attitudes together with knowledge and skills and are not specific. Furthermore, there is variability in the instruments used to evaluate the effectiveness of educational interventions. For example, Breitkreuz et al. [39] compared the use of videos and simulation to improve nursing students' attitudes towards patient safety, concluding that simulation was more effective. Kim et al. [19] compared the flipped classroom methodology with regular teaching in a sample of 75 nursing students. The authors concluded that their intervention managed to significantly improve knowledge and skills related to patient safety, but not attitudes, mainly in final year students. Maxwell et al. [18] obtained similar results using the flipped classroom methodology, although in their study there was no control group and different instruments were used to evaluate the effectiveness of the interventions.

Mansour et al. [14] evaluated whether knowledge and attitudes about patient safety improved in a sample of 141 English nursing students after two master classes and facilitated group work, but the results of this pre-post-intervention study were not significant. Another study with 59 Dutch nursing students obtained satisfactory results after applying a structured program on patient safety, but the authors used an ad hoc questionnaire to globally assess the competencies established by the WHO and not the acquisition of knowledge, skills and attitudes [15]. Other authors also did not find significant differences in attitudes towards patient safety when they evaluated different educational interventions [40,41].

In our study, Phase I of the educational intervention took place in the classroom, while Phase II was carried out during clinical practice. It should be mentioned that the score of the questionnaire increased slightly between the intermediate and the final measurement, although not significantly, indicating that the clinical practices did not negatively affect students' attitudes. On the one hand, our students receive structured 
training on patient safety for the first time in the subject where the intervention was carried out, and this could explain why Phase I of the intervention significantly improved their attitudes towards patient safety. On the other hand, Lukewich et al. [42] observed that attitudes toward patient safety in nursing students decreased as their contact with clinical practices increased. It is possible that the level of safety culture of the units where students carry out the clinical practices [26], the quality of the learning environment [42] or the role played by clinical tutors as models for students [43] may influence these results. In the same way, these factors can help to explain the significant differences found in the final measurement when comparing the results between both courses, as practice units are awarded each year according to the centers' addresses, and both the units and the clinical practice tutors may change. Future studies should consider the influence of these factors.

Despite this, integrating patient safety education into clinical practice and reducing the gap between theory and practice is a common recommendation to improve the patient safety competencies of nursing students. Although it is not clear what the best strategies for this are $[9,12,13]$, the results of our study can help in this regard.

The version of the APSQ-III used in this study for nursing students has 22 items organized in six dimensions (Responsibility, Organization and Communication; Teamwork; Training; Notification; Awareness) that are directly related to patient safety. The dimensions Teamwork and Organization and Communication are related to a fundamental principle of patient safety, which is that errors in medical care depend more on failures in the system and in the design of processes than on human errors [44]. This is also related to the Responsibility and Awareness dimensions, although the aim here is to assess how students perceive responsibility for adverse effects and the need to communicate undesirable results to patients if they occur [45]. The Notification dimension refers to the attitude of students towards the reporting of errors to managers, which is a fundamental aspect in improving patient safety [46]. Finally, the Training dimension focuses on the importance of education in understanding the causes of errors and adverse effects [1-6]. Other questionnaires on patient safety in nursing students present similar structures and dimensions that address the same concepts [47].

The educational intervention evaluated in this study began with the analysis of a real case that affected patient safety. This case focuses on an error in the administration of medication, one of the main causes of adverse effects [48], and ends with the death of the patient. In the analysis of the case with the RCA technique, a chain of system failures and human errors were observed, mainly related to communication problems, one of the main root causes of errors [49]. The guided reflection after the analysis of the case made it possible to address aspects related to the organization of the processes and responsibility for errors, considering that initially the nurses were found guilty and, after the real analysis of the case with the RCA technique, it could be shown that they were not directly responsible for the death of the patient. In addition, during Phase II of the intervention, the students relied on real cases that they experienced during clinical practice to reflect on patient safety and apply the contents and techniques addressed in the classroom. Thus, the educational content used can influence nursing students' attitudes towards patient safety and are linked to the dimensions of the APSQ-III.

In our study, the dimensions that obtained the highest scores were Organization and Communication and Teamwork, while the Notification and Responsibility dimensions obtained the lowest scores. These results partially coincide with those of other authors [50], where the best results were obtained in aspects related to communication and the worst in aspects related to teamwork. However, students carry out clinical practice with more experienced nurses and they are expected to be able to work in teams and communicate professionally with their colleagues and also with patients. In addition, students are expected to be cautious, ask the nurses when in doubt and notify them if they make a mistake. However, nursing students are unwilling to report adverse effects and their motives need to be understood in order to improve their attitudes towards reporting [24-26]. 
Regarding the influence of sociodemographic variables, several aspects should be discussed. On the one hand, only significant differences were observed in the APSQ-III score based on previous studies in the intermediate measurement. In addition, it was observed how the score decreased along the three measurements in students with previous professional training and how students with other types of training (for example, first aid courses or training as lifeguards) had the highest score. However, it must be taken into account that the majority of students did not have any type of previous training and that the other subsamples of this variable were not very representative, which could affect the results. Otherwise, the influence of previous studies of nursing students on their attitudes towards patient safety should be addressed in greater depth in future research, since no previous studies were found that considered this variable.

On the other hand, the variable employment situation had a significant influence on the three measures. Thus, students who were unemployed obtained higher scores than those who were working, possibly due to a greater availability of time to go to class and dedicate themselves to studying [41]. In addition, it is striking that the students who already worked in the health field obtained significantly lower scores than the rest and it is necessary to highlight that the score of these students who already worked in the health field decreased over the three measurements. These results deserve further study and are probably related to a low culture of patient safety in their work centers, although there are few studies on safety culture in our context [51]. These results have implications for future education if it is considered that, at least in our case, patient safety education is atomized into one subject and this may be insufficient for an adequate acquisition of competencies related to patient safety and, specifically, to develop or modify attitudes towards patient safety. Meanwhile, different authors recommend that competencies in patient safety be addressed throughout the different academic courses and are linked to experiences related to patient safety during clinical practice $[9,43]$. Finally, the results of this study should be viewed with caution due to their limitations. On the one hand, it is a quasi-experimental before and after study, with a non-randomized sample and no control group, which was carried out in a single institution, limiting the generalizability of the results. Furthermore, the long-term effectiveness of the intervention was not studied, and the results are based on self-report by the students, with a risk of information bias. Despite these limitations, the results of this study are of interest, as studies evaluating educational interventions to improve attitudes towards patient safety in nursing students are limited and few of them report a significant improvement in the attitudes of nursing students. In addition, the implications for practice should be considered, as improving nursing students' attitudes towards patient safety should improve certain behaviors, such as reporting adverse effects, teamwork and communication with patients when they work as nurses. Thus, a direct impact on improving the quality of healthcare should be expected. The intervention offers an alternative with favorable results, although it is necessary to carry out studies with more robust experimental designs and larger samples to confirm the results obtained.

\section{Conclusions}

This quasi-experimental study evaluated the effectiveness of an educational intervention on attitudes towards patient safety in nursing students. The results showed a significant global improvement in the attitudes of the sample studied and attitudes remain positive when students are exposed to the reality of clinical practice. These results should be confirmed in future studies with more robust designs that consider factors such as the quality of the learning environment, the level of safety culture of the practice units or the influence of the practice tutors in the acquisition of skills related to patient safety.

Author Contributions: Conceptualization, V.M.G.-C. and N.C.-L.; methodology, D.M.-T., Á.C.-G. and V.M.G.-C.; formal analysis, N.C.-L. and M.J.V.-C.; writing-original draft preparation, V.M.G.C. and L.A.-P.; writing-review and editing, R.V.-C.; project administration, V.M.G.-C.; funding acquisition, V.M.G.-C. and N.C.-L. All authors have read and agreed to the published version of the manuscript. 
Funding: This research was funded by Ministerio de Educación y Formación Profesional, grant number 19CO1/000156.

Institutional Review Board Statement: The study was conducted according to the guidelines of the Declaration of Helsinki and approved and authorized by the Nursing Department Council of the Universitat Jaume I (project reference 19CO1/000156).

Informed Consent Statement: Informed consent was obtained from all subjects involved in the study.

Data Availability Statement: The data presented in this study are available on request from the corresponding author.

Conflicts of Interest: The authors declare no conflict of interest.

\section{References}

1. World Health Organization. Available online: https://www.who.int/patientsafety/education/mp_curriculum_guide/en/ (accessed on 29 December 2020).

2. Institute of Medicine (US) Committee on the Health Professions Education Summit. Health Professions Education: A Bridge to Quality; Greiner, A.C., Knebel, E., Eds.; National Academies Press: Washington, DC, USA, 2003.

3. Cronenwett, L.; Sherwood, G.; Barnsteiner, J.; Disch, J.; Johnson, J.; Mitchell, P.; Sullivan, D.T.; Warren, J. Quality and safety education for nurses. Nurs. Outlook 2007, 55, 122-131. [CrossRef] [PubMed]

4. Walton, M.M.; Shaw, T.; Barnet, S.; Ross, J. Developing a national patient safety education framework for Australia. Qual. Saf. Health Care 2006, 15, 437-442. [CrossRef] [PubMed]

5. Canadian Patient Safety Institute. Available online: https://www.patientsafetyinstitute.ca/en/toolsResources/safetyCompetencies/ Pages/default.aspx (accessed on 29 December 2020).

6. European Patients Forum. Available online: https://www.eu-patient.eu/globalassets/projects/eunetpas/guidelines_final_22-0 6-2010.pdf (accessed on 29 December 2020).

7. Lee, N.-J.; Jang, H.; Park, S.-Y. Patient safety education and baccalaureate nursing students' patient safety competency: A cross-sectional study. Nurs. Health Sci. 2015, 18, 163-171. [CrossRef]

8. Mira, J.J.; Guilabert, M.; Vitaller, J.; Ignacio, E. Formación en seguridad del paciente en las escuelas de medicina y enfermería en España. Rev. de Calid. Asist. 2016, 31, 141-145. [CrossRef] [PubMed]

9. Kirwan, M.; Riklikienè, O.; Gotlib, J.; Fuster, P.; Borta, M.; Evridiki, P.; Chryssoula, L.; Walter, S.; Maria, S.; Riitta, S.; et al. Regulation and current status of patient safety content in pre-registration nurse education in 27 countries: Findings from the Rationing-Missed nursing care (RANCARE) COST Action project. Nurse Educ. Pr. 2019, 37, 132-140. [CrossRef] [PubMed]

10. Levett-Jones, T.; Andersen, P.; Bogossian, F.; Cooper, S.; Guinea, S.; Hopmans, R.; McKenna, L.; Pich, J.; Reid-Searl, K.; Seaton, P. A cross-sectional survey of nursing students' patient safety knowledge. Nurse Educ. Today 2020, 88, 104372. [CrossRef]

11. Niemeyer, M. Effective patient safety education for novice RNs: A systematic review. J. Nurs. Educ. Pr. 2017, 8, 103. [CrossRef]

12. Bianchi, M.; Bressan, V.; Cadorin, L.; Pagnucci, N.; Tolotti, A.; Valcarenghi, D.; Watson, R.; Bagnasco, A.; Sasso, L. Patient safety competencies in undergraduate nursing students: A rapid evidence assessment. J. Adv. Nurs. 2016, 72, 2966-2979. [CrossRef]

13. Lee, S.E.; Morse, B.L. Incorporating medication administration safety in undergraduate nursing education: A literature review. Nurse Educ. Today 2019, 72, 77-83. [CrossRef]

14. Mansour, M.; Skull, A.; Parker, M. Evaluation of World Health Organization Multi-Professional Patient Safety Curriculum Topics in Nursing Education: Pre-test, post-test, none-experimental study. J. Prof. Nurs. 2015, 31, 432-439. [CrossRef]

15. Olaf, T.; Mieke, D.V.; Eric, F. The Effectiveness of a Course on Patient Safety Management on the Patient Safety Competencies by Final Year Bachelor of Nursing Students in the Netherlands. Health Educ. Care 2016, 2, 1-5. [CrossRef]

16. Hewitt, J.; Tower, M.; Latimer, S.L. An education intervention to improve nursing students' understanding of medication safety. Nurse Educ. Pr. 2015, 15, 17-21. [CrossRef] [PubMed]

17. Lobos, B.M.; Vergara, N.F. Efecto de un Programa de Intervención Educativa Sobre el Conocimiento de Seguridad de Pacientes en Estudiantes de Pregrado de Enfermería. Ciencia Enferm. 2017, 23, 97-108. [CrossRef]

18. Maxwell, K.L.; Wright, V.H. Evaluating the Effectiveness of Two Teaching Strategies to Improve Nursing Students' Knowledge, Skills, and Attitudes About Quality Improvement and Patient Safety. Nurs. Educ. Perspect. 2016, 37, 291-292. [CrossRef] [PubMed]

19. Kim, Y.M.; Yoon, Y.S.; Hong, H.C.; Min, A. Effects of a patient safety course using a flipped classroom approach among undergraduate nursing students: A quasi-experimental study. Nurse Educ. Today 2019, 79, 180-187. [CrossRef]

20. García-Gámez, M.; Morales-Asencio, J.M.; García-Mayor, S.; Kaknani-Uttumchandani, S.; Martí-García, C.; Lopez-Leiva, I.; León-Campos, Á.; Fernandez-Ordoñez, E.; García-Guerrero, A.; Iglesias-Parra, M.R. A scoping review of safety management during clinical placements of undergraduate nursing students. Nurs. Outlook 2019, 67, 765-775. [CrossRef]

21. Bickel, A.E.; Villasecas, V.X.; Fluxá, P.J.; Dickel, A.E.; Villasecas, X.V.; Fluxá, J.P. Characterization of adverse events occurring during nursing clinical rotations: A descriptive study. Nurse Educ. Today 2020, 84, 104224. [CrossRef] 
22. García-Gámez, M.; Asencio, J.M.M.; García-Mayor, S.; Kaknani-Uttumchandani, S.; Martí-García, C.; Lopez-Leiva, I.; LeónCampos, Á.; Fernandez-Ordoñez, E.; García-Guerrero, A.; Iglesias-Parra, R. Adverse events encountered during clinical placements by undergraduate nursing students in Spain. Nurse Educ. Today 2020, 91, 104480. [CrossRef]

23. Chassin, M.R.; Loeb, J.M. High-Reliability Health Care: Getting There from Here. Milbank Q. 2013, 91, 459-490. [CrossRef]

24. Palese, A.; Gonella, S.; Grassetti, L.; Mansutti, I.; Brugnolli, A.; Saiani, L.; Terzoni, S.; Zannini, L.; Destrebecq, A.; Dimonte, V.; et al. Multi-level analysis of national nursing students' disclosure of patient safety concerns. Med. Educ. 2018, 52, 1156-1166. [CrossRef]

25. Halperin, O.; Bronshtein, O.; Ofra, H.; Bronshtein, O. The attitudes of nursing students and clinical instructors towards reporting irregular incidents in the medical clinic. Nurse Educ. Pr. 2019, 36, 34-39. [CrossRef] [PubMed]

26. Kong, L.-N.; Zhu, W.-F.; He, S.; Chen, S.-Z.; Yang, L.; Qi, L.; Peng, X. Attitudes towards patient safety culture among postgraduate nursing students in China: A cross-sectional study. Nurse Educ. Pr. 2019, 38, 1-6. [CrossRef] [PubMed]

27. Neal, A.; Griffin, M.A. A study of the lagged relationships among safety climate, safety motivation, safety behavior, and accidents at the individual and group levels. J. Appl. Psychol. 2006, 91, 946-953. [CrossRef] [PubMed]

28. González-Fernández, N.; Lobato-Fraile, C. Evaluación de las competencias sociales en estudiantes de enfermería. Bordón. Rev. Pedag. 2008, 60, 91-106.

29. Steven, A.; Wilson, G.; Turunen, H.; Vizcaya-Moreno, M.F.; Azimirad, M.; Kakurel, J.; Porras, J.; Tella, S.; Pérez-Cañaveras, R.; Sasso, L.; et al. Critical Incident Techniques and Reflection in Nursing and Health Professions Education. Nurse Educ. 2020, 45, E57-E61. [CrossRef] [PubMed]

30. Dolansky, M.A.; Druschel, K.; Helba, M.; Courtney, K. Nursing Student Medication Errors: A Case Study Using Root Cause Analysis. J. Prof. Nurs. 2013, 29, 102-108. [CrossRef]

31. Schluter, J.; Seaton, P.; Chaboyer, W. Critical incident technique: A user's guide for nurse researchers. J. Adv. Nurs. 2007, 61, 107-114. [CrossRef]

32. Mena-Tudela, D.; González-Chordá, V.M.; Cervera-Gasch, A.; Maciá-Soler, M.L.; Orts-Cortés, M.I. Effectiveness of an EvidenceBased Practice educational intervention with second-year nursing students. Rev. Lat. Am. Enferm. 2018, 26, e3026. [CrossRef]

33. Peerally, M.F.; Carr, S.; Waring, J.; Dixon-Woods, M. The problem with root cause analysis. BMJ Qual. Saf. 2016, 26, 417-422. [CrossRef]

34. Carter, A.G.; Sidebotham, M.; Creedy, D.K.; Fenwick, J.; Gamble, J. Using root cause analysis to promote critical thinking in final year Bachelor of Midwifery students. Nurse Educ. Today 2014, 34, 1018-1023. [CrossRef]

35. Smetzer, J.L. Lesson from Colorado. Beyond blaming individuals. J. Nurs. Managt. 1998, 29, 49-51.

36. Cursos Seguridad del Paciente. Available online: https://cursos.seguridaddelpaciente.es/formacion-seguridad-pacienteprevencion-eventos-adversos-asistencia-sanitaria/ (accessed on 29 December 2020).

37. Carruthers, S.; Lawton, R.; Sandars, J.; Howe, A.; Perry, M. Attitudes to patient safety amongst medical students and tutors: Developing a reliable and valid measure. Med. Teach. 2009, 31, e370-e376. [CrossRef] [PubMed]

38. Lamponi, T.L.; Gazzoni, C.; Gallardo, M.F.; Cragno, A.; García Diéguez, M.; Ocampo, A. Seguridad del paciente y educación médica: Adaptación transcultural de un cuestionario para la evaluación de la percepción de seguridad del paciente en estu-diantes de medicina. Rev. Argent. Educ. Méd. 2014, 6, 45-52.

39. Breitkreuz, K.R.; Dougal, R.L.; Wright, M.C. How Do Simulated Error Experiences Impact Attitudes Related to Error Prevention? Simul. Health J. Soc. Simul. Health 2016, 11, 323-333. [CrossRef] [PubMed]

40. Ardizzone, L.L.; Enlow, W.M.; Evanina, E.Y.; Schnall, R.; Currie, L. Impact of a Patient Safety Curriculum for Nurse Anesthesia Students. J. Nurs. Educ. 2009, 48, 706-710. [CrossRef]

41. Marchi, N.M.; Dolansky, M. Using Active Learning to Foster Patient Safety Knowledge, Perceived Skills, and Attitudes in Baccalaureate Nursing Students. Nurs. Educ. Perspect. 2017, 38, 146-148. [CrossRef]

42. Lukewich, J.; Edge, D.S.; Tranmer, J.; Raymond, J.; Miron, J.; Ginsburg, L.R.; VanDenKerkhof, E.G. Undergraduate baccalaureate nursing students' self-reported confidence in learning about patient safety in the classroom and clinical settings: An annual cross-sectional study (2010-2013). Int. J. Nurs. Stud. 2015, 52, 930-938. [CrossRef]

43. Amsrud, K.E.; Lyberg, A.; Severinsson, E. The influence of clinical supervision and its potential for enhancing patient safetyUndergraduate nursing students' views. J. Nurs. Educ. Pr. 2015, 5, 87. [CrossRef]

44. Hershey, K. Culture of Safety. Nurs. Clin. North Am. 2015, 50, 139-152. [CrossRef]

45. Paudyal, V.; Al-Hamid, A.; Bowen, M.; Hadi, M.A.; Hasan, S.S.; Jalal, Z.; Stewart, D. Interventions to improve spontaneous adverse drug reaction reporting by healthcare professionals and patients: Systematic review and meta-analysis. Expert Opin. Drug Saf. 2020, 19, 1173-1191. [CrossRef]

46. Barrachina, A.; González-Chordá, V.M. Error reporting and the performance of nursing management: A game-theoretic study. IMA J. Manag. Math. 2020, 31, 445-468. [CrossRef]

47. Mira, J.J.; Navarro, I.M.; Guilabert, M.; Poblete, R.; Franco, A.L.; Jiménez, P.; Aquino, M.; Fernández-Trujillo, F.J.; Lorenzo, S.; Vitaller, J.; et al. A Spanish-language patient safety questionnaire to measure medical and nursing students' attitudes and knowledge. Rev. Panam. Salud Púb. 2015, 38, 110-119.

48. Manias, E.; Kusljic, S.; Wu, A. Interventions to reduce medication errors in adult medical and surgical settings: A systematic review. Ther. Adv. Drug Saf. 2020, 11. [CrossRef] [PubMed]

49. Chatman, I.J. The Joint Commission Guide to Improving Staff Communication; Joint Commission Resources: Oak Brook, IL, USA, 2005. 
50. Hwang, J.-I.; Yoon, T.-Y.; Jin, H.-J.; Park, Y.; Park, J.-Y.; Lee, B.-J. Patient safety competence for final-year health professional students: Perceptions of effectiveness of an interprofessional education course. J. Interprof. Care 2016, 30, 732-738. [CrossRef] [PubMed]

51. Martí, V.B.; Orts-Cortés, M.I.; Maciá-Soler, M.L. Percepción de los profesionales de enfermería y auxiliares de enfermería sobre cultura de seguridad del paciente en el área quirúrgica. Enferm. Clín. 2015, 25, 64-72. [CrossRef] [PubMed] 